\title{
ANALYSIS OF VOLUME AND IMPACT OF SOLID WASTE GROWTH IN KUKIN VILLAGE SUMBAWA REGENCY
}

\section{Analisis Volume dan Dampak Timbulan Sampah Padat di Desa Kukin Kabupaten Sumbawa}

\section{Iga Maliga, Herni Hasifah*, Desy Fadilah Adina Putri}

STIKES Griya Husada Sumbawa

*Alamat Korespondensi: yenihasifah@gmail.com

\section{Article Info}

\section{Article History}

Received: 08 Des 2021

Revised : 16 Des 2021

Accepted : 21 Des 2021

\section{Keywords :}

Impact, Waste accumulation, Waste volume

\section{Kata kunci :}

Dampak, Timbulan

sampah, Volume

sampah

\begin{abstract}
ABSTRAK
Population growth and the improvement of the current economic conditions of Indonesian society, without us knowing it, have caused the quality of the environment to decline. We can see a decrease in the quality of the environment from the many environmental conditions that have experienced degradation or a decrease in environmental quality caused by environmental pollution. Kukin Village is one of the areas in Sumbawa Sub-district which is densely populated and has not had access to a garbage truck. This study aims to determine the amount of waste generated in Kukin Village and to determine the impact caused by the accumulation of existing waste generation. This research used a combination of quantitative and qualitative descriptive methods. Sample of this study were 40 housewives as respondents who were taken by purposive sampling. The process of taking daily waste sampling data was carried out for 7 days. In-depth interviews and observations are used as a form of making a matrix of impacts felt by residents. The impact matrix involves socio-cultural, health and environmental aspects. The results showed that the average daily waste generation rate was $32.6 \mathrm{~kg}$, the average daily waste generation per person was $0.82 \mathrm{~kg}$ and the solid waste generation density was $190 \mathrm{~kg} / \mathrm{L}$. The process of predicting negative impacts that occur on the environment using the matrix method as a result of landfilling in the Kukin Village area can cause impacts related to geophysical conditions, biotic conditions and social, economic and cultural conditions.
\end{abstract}

Pertumbuhan penduduk dan membaiknya kondisi ekonomi masyarakat Indonesia saat ini tanpa kita sadari telah menyebabkan kualitas lingkungan menurun. Penurunan kualitas lingkungan dapat kita lihat dari banyaknya kondisi lingkungan yang mengalami degradasi atau penurunan kualitas lingkungan akibat pencemaran lingkungan. Desa Kukin merupakan salah satu wilayah di Kecamatan Sumbawa yang berpenduduk padat dan belum memiliki akses truk sampah. Penelitian ini bertujuan untuk mengetahui jumlah sampah yang dihasilkan di Desa Kukin, Kabupaten Sumbawa dan untuk mengetahui dampak yang ditimbulkan dari akumulasi timbulan sampah yang ada. Penelitian ini menggunakan kombinasi metode deskriptif kuantitatif dan kualitatif. Sampel penelitian ini sebanyak 40 ibu rumah tangga sebagai responden yang diambil secara purposive sampling. Proses pengambilan data sampling sampah harian dilakukan selama 7 hari. Wawancara mendalam dan observasi digunakan sebagai bentuk pembuatan matriks dampak yang dirasakan warga. Matriks dampak melibatkan aspek sosial budaya, kesehatan dan lingkungan. Hasil penelitian menunjukkan bahwa ratarata timbulan sampah harian $32,6 \mathrm{~kg}$, rata-rata timbulan sampah harian per orang 0,82 $\mathrm{kg}$ dan kepadatan timbulan sampah $190 \mathrm{~kg} / \mathrm{L}$. Proses prediksi dampak negatif yang terjadi terhadap lingkungan menggunakan matriks Akibat dari penimbunan di kawasan Desa Kukin dapat menimbulkan dampak yang berkaitan dengan kondisi geofisika, kondisi biotik dan kondisi sosial, ekonomi dan budaya. 


\section{PENDAHULUAN}

Sampah adalah barang yang dianggap sudah tidak terpakai dan dibuang oleh pemilik/pemakai sebelumnya, tetapi bagi sebagian orang masih bisa dipakai jika dikelola dengan prosedur yang benar (Nugroho, 2014). Penumpukan sampah disebabkan oleh beberapa faktor, diantaranya adalah volume sampah yang sangat besar sehingga melebihi kapasitas daya tampung tempat pembuangan sampah akhir (TPA). Pengelolaan sampah yang terjadi selama ini dirasakan tidak memberikan dampak positif kepada lingkungan, dan kurangnya dukungan kebijakan dari pemerintah. Batasan ini jelas bahwa sampah adalah hasil kegiatan manusia yang dibuang karena sudah tidak digunakan dan disebut sampah. Dengan demikian sampah mengandung prinsip sebagai berikut:

1. Adanya sesuatu benda atau bahan padat.

2. Adanya hubungan langsung atau tidak langsung dengan manusia

3. Benda atau bahan tersebut tidak dipakai lagi.

Timbulan sampah adalah sejumlah sampah yang dihasilkan oleh suatu aktifitas dalam kurun waktu tertentu atau dengan kata lain banyaknya sampah yang dihasilkan dalam satuan berat (kilogram) gravimetri atau volume (liter) volumetri (Tchobanoglous, et, al 1993 dalam Ramandhani, 2011). Prakiraan timbulan sampah baik untuk saat sekarang atau maupun di masa mendatang merupakan dasar dari perencanaan, perancangan, dan pengkajian sistem pengelolaan persampahan (Damanhuri, 2004 dalam Ramandhani, 2011).

Timbulan sampah di Kabupaten Sumbawa masih menjadi permasalahan yang krusial. Hal ini disebabkan karena proses pengelolaan sampah hanya sebatas penimbunan (land fill) belum menjalani tahap yang lebih lanjut tanpa adanya proses pemilahan sampah organik maupun anorganik. pelayanan sampah kepada masyarakat menjangkau $52,6 \%$ wilayah Kabupaten Sumbawa. Sampai tahun 2010 jumlah sampah yang terlayani adalah $41.573,52 \mathrm{~m}^{3} /$ thn (53\%), dengan jumlah yang terbesar berasal dari kecamatan Sumbawa. Sebagian besar sampah tersebut diolah di TPA Raberas yang di rencanakan sebagai tempat pembuangan sampah terpadu. Berdasarkan data dari MPSS Kabupaten Sumbawa (2018), volume sampah perhari di Kota Sumbawa sebanyak $115,482 \mathrm{~m}^{3} /$ hari dengan total sampah domestik sebesar 67,842 $\mathrm{m}^{3} /$ hari. Kapasitas pengelolaan sampah di Kabupaten Sumbawa dengan cakupan pelayanan wilayah perkotaan rata-rata baru $52 \%$ (terdiri dari kecamatan Sumbawa $179 \mathrm{~m}^{3} /$ hari dengan 52\% terangkut. Kecamatan Labuhan Badas dengan timbulan sampah $96 \mathrm{~m}^{3} /$ hari demgan 55\% terangkut, dan Kecamatan Unter Iwis dengan timbulan sampah $77 \mathrm{~m}^{3} /$ hari dengan $49 \%$ terangkut). Sedangkan cakupan pelayanan di wilayah perdesaan masih 4,19\%. Hal ini menunjukkan masih rendahnya kualitas dan tingkat pengelolaan Persampahan di Kabupaten Sumbawa. Masih banyak wilayah lain yang ada di Kabupaten Sumbawa yang belum terjangkau oleh akses pengangkutan sampah.

Desa Kukin merupakan salah satu wilayah yang ada di Kecamatan Sumbawa, Kabupaten Sumbawa, yang padat pemukiman dan belum mendapatkan akses pengangkutan truk sampah. Seringkali permasalahan sampah ini menjadi permasalahan klasik yang dihadapi oleh masyarakat. Sehingga dengan demikian peneliti tertarik untuk melakukan penelitian terkait dengan volume timbulan sampah padat yang dihasilkan di Desa Kukin dan mencari dampak yang disebabkan oleh timbulan sampah tersebut baik segi aspek kesehatan maupun lingkungan.

\section{BAHAN DAN METODE}

Penelitian ini menggunakan metode kuantitatif deskriptif. Penelitian kuantitatif yang dilakukan berbentuk studi analisis untuk mengidentifikasi timbulan dan komposisi sampah, serta penelitian kualitatif dalam bentuk wawancara mendalam terkait dampak yang disebabkan oleh timbulan sampah. 
Penelitian ini dilakukan pada bulan Oktober 2021 berlokasi di Desa Kukin Kecamatan Moyo Utara dengan jumlah responden 40 orang yang dipilih secara purposive sampling. Pengumpulan data yang digunakan dengan metode observasi lapangan dan wawancara mendalam serta penggunaan matriks kemungkinan dampak yang diperkirakan akan muncul sebagai dampak dari penimbunan sampah yang terus menerus.

Pengambilan sampel dilakukan dengan purposive sampling method. Data primer didapatkan dengan kuesioner dan wawancara langsung kepada ibu rumah tangga, karena mereka yang lebih banyak berperan dalam mengurus kegiatan rumah tangga termasuk dalam hal pengelolaan sampahnya. Kriteria eksklusif dalam penelitian ini adalah (1) Ibu rumah tangga berusia 25-40 tahun, (2) ibu rumah tangga yang aktif mengurus sampah rumah tangga sehari-hari, (3) ibu rumah tangga yang bisa membaca dan tidak mengalami gangguan jiwa.

\section{HASIL}

Berdasarkan hasil olah data, responden yang merupakan ibu-ibu mayoritas berada pada usia lebih dari 45 tahun. Hal ini ditunjukkan dengan banyaknya responden yang berumur lebih dari 45 tahun sebanyak 33,3\%. Aspek kepemilikan rumah, hampir seluruh responden memiliki rumah dengan kepemilikan sendiri. Selain itu pada aspek kependidikan, mayoritas responden merupakan lulusan SD dengan persentase sebanyak 35,9\%.

Tabel 1. Karakteristik Responden

\begin{tabular}{llc}
\hline \multicolumn{1}{c}{ Karakteristik Responden } & & $\%$ \\
\hline A1. Kelompok Umur Responden & $<=20$ tahun & 2.6 \\
& $21-25$ tahun & 10.3 \\
& $26-30$ tahun & 12.8 \\
& $31-35$ tahun & 12.8 \\
& $36-40$ tahun & 10.3 \\
B2. Status kepemilikan rumah & $41-45$ tahun & 17.9 \\
& $>45$ tahun & 33.3 \\
& Milik sendiri & 87.2 \\
B3. Pendidikan terakhir & Rumah dinas & .0 \\
& Berbagi dengan keluarga lain & .0 \\
& Kontrak & .0 \\
& Milik orang tua & 12.8 \\
& Tidak sekolah formal & 12.8 \\
B4. Kepemilikan Surat at Keterangan Tidak Mampu (SKTM) & SD & 35.9 \\
dari desa/kelurahan & YMP & 25.6 \\
B5. Kepemilikan Kartu Asuransi Kesehatan bagi Keluarga & Tidak & 12.8 \\
Miskin (ASKESKIN) & Ya & .0 \\
\hline Sum & Tidak & 12.8 \\
& & 12.8 \\
& SMK & 87.2 \\
& Universitas/Akademi & 76.9 \\
& & 23.1 \\
\hline
\end{tabular}

Sumber: Data Primer, 2021.

Tabel 2 menunjukkan bahwa kondisi sampah yang ada di lokasi penelitian. Sampah di lingkungan sekitar terkait dengan tumpukan sekitar lokasi penelitian berserakan dan 
bertumpuk sehingga menyebabkan banyak lalat di sekitar tumpukan sampah tersebut. Ricky (2005) dalam Kumala dan Pawenang (2017), limbah padat yang tidak disimpan dengan baik dapat menjadi tempat bersarangnya vektor penyakit seperti tikus dan lalat. Tikus dan lalat menjadi salah satu vector penyakit yang menyebabkan penyakit diare. Hal ini menjadi pemicu dalam meningkatnya penyakit diare yang ada di wilayah penelitian. Hal ini sesuai dengan hasil survey BPS Moyo Utara dalam Angka (2019), bahwa penyakit diare mendominasi di wilayah ini.

Tabel 2. Kondisi Sampah di Lingkungan Sekitar Wilayah Penelitian

\begin{tabular}{ll}
\hline \multicolumn{1}{c}{ Kondisi } & Persentase (\%) \\
\hline Banyak sampah berserakan atau bertumpuk di sekitar lingkungan & 82.1 \\
\hline Banyak lalat di sekitar tumpukan sampah & 69.2 \\
\hline Banyak tikus berkeliaran & 5.1 \\
Banyak nyamuk & 30.8 \\
Banyak kucing dan anjingmendatangi tumpukan sampah & 53.8 \\
Bau busuk yang menggangu & 5.1 \\
Menyumbat saluran drainase & 7.7 \\
\hline Ada anak-anak yang bermain di sekitar tumpukan sampah & 15.4 \\
\hline
\end{tabular}

Sumber: Data Primer, 2021

Tabel 3. Proses Pengelolaan Sampah Rumah Tangga

\begin{tabular}{llc}
\hline Item Pengelolaan & Opsi & Persentase (\%) \\
\hline Pengelolaan & sampah & .0 \\
rumah tangga & Dikumpulkan oleh kolektor informal yang mendaur ulang & \\
& Dikumpulkan dan dibuang ke TPS & 30.0 \\
& Dibakar & 2.5 \\
& Dibuang ke dalam lubang dan ditutup dengan tanah & .0 \\
& Dibuang ke dalam lubang tetapi tidak ditutup dengan tanah & 15.0 \\
& Dibuang ke sungai/kali/laut/danau & 52.5 \\
& Dibuang ke lahan kosong/kebun/hutan dan dibiarkan & \\
& membusuk & .0 \\
\hline Total & Lain-lain & $\mathbf{1 0 0}$ \\
\hline
\end{tabular}

Sumber: Data Primer, 2021

\section{PEMBAHASAN}

Pengelolaan sampah merupakan aspek yang memegang peranan penting dalam kondisi lingkungan sekitar. Menurut Windraswara dan Prihastuti (2017), pengelolaan sampah perkotaan merupakan salah satu tantangan besar yang harus dihadapi daerah perkotaan di negaranegara berkembang. Menurut Damanhuri (2005), sampah dikategorikan menjadi sampah permukiman, atau disebut juga sampah rumah tangga, yaitu sampah yang dihasilkan dari kegiatan rumah tangga sehari-hari seperti dari dapur, serta sampah non-permukiman, yaitu sampah yang berasal dari kawasan komersial dan fasilitas umum seperti toko, pasar, sekolah, kantor dan sebagainya. Peningkatan populasi, pertumbuhan ekonomi, urbanisasi dan industrialisasi meningkatkan jumlah timbulan sampah yang diproduksi. Pengelolaan sampah suatu kota bertujuan untuk melayani sampah yang dihasilkan penduduk. Berdasarkan SNI 3242:2008, faktor penentu dalam memilih teknik operasional pengelolaan yang akan diterapkan 
adalah kondisi topografi dan lingkungan daerah pelayanan, kondisi sosial, ekonomi, partisipasi masyarakat, jumlah dan jenis timbulan sampah (Badan Standarisasi Nasional, 2008).

Saat ini pengelolaan persampahan menghadapi banyak tekanan terutama akibat semakin besarnya sumber sampah dari penghasil sampah. Hal ini menjadi semakin berat dengan masih dimilikinya paradigma lama (Masrida, 2017). Sumber utama sampah di Indonesia adalah sampah rumah tangga, yang sebagian besar (50-70\%) merupakan sampah yang mudah membusuk berasal dari sisa makanan, kulit buah, sayuran, dan lain sebagainya (Trihadiningrum et al., 2015). Salah satu pengelolaan sampah yang baik adalah yang memisahkan jenis-jenis sampah pada tempat sampah yang berbeda atau biasa disebut sebagai pemilahan sampah yang dilakukan di rumah masing-masing. Jika hal ini dilakukan maka akan mengurangi timbulan sampah pada TPS sekitar.

Faktanya, banyak kondisi yang membuat masyarakat untuk tidak melakukan pemilahan sampah yang ada di rumah masing-masing. Limbah padat atau Sampah menurut Tchobanouglous et al (1993) dalam Lesmana (2017), merupakan bahan buangan yang berbentuk padat maupun semi padat yang berasal dari aktifitas manusia maupun hewan yang dibuang karena tidak memiliki manfaat bagi pemiliknya. Banyak limbah padat perkotaan yang dihasilkan hanya masuk ke Tempat Pembuangan Sampah (TPS) dan setelah itu dibiarkan begitu saja hingga menumpuk. Proses pengelolaan ini secara sederhana tidak berdampak baik bagi lingkungan. Hal ini sama saja dengan memindahkan tempat sampah yang tadinya berasal dari rumah ke tempat lain tanpa adanya upaya untuk mereduksi jumlah sampah.

Berdasarkan data yang diperoleh dari sipsn.menlhk.go.id (2018), jumlah timbulan sampah kabupaten Sumbawa yang dihasilkan adalah sebanyak 310.00 Ton/hari. Beberapa indikator yang digunakan dalam ukuran keberhasilan dalam melakukan pengelolaan sampah adalah jumlah penduduk terlayani, tingkat pelayanan sampah, dan aspek teknis TPA yang meliputi proses pengangkutan, sarana dan prasarana. Merujuk pada aturan terkait dengan pengelolaan sampah pada Undang-Undang tahun 2008, bahwa kondisi serta masalah sampah merupakan hal yang tidak hanya menjadi tanggungjawab pemerintah tetapi juga tanggungjawab masyarakat.

Desa Kukin adalah salah satu desa yang berada di Kecamatan Moyo Utara. Kecamatan Moyo Utara berada di Kabupaten Sumbawa yang masuk dalam salah satu Kabupaten yang masuk dalam kategori 3T. Desa ini memiliki luas wilayah sebesar 1.100 Ha dengan jumlah total penduduk 1.302 jiwa (BPS, 2019). Desa ini masih terbatas dalam proses pengelolaan sampah secara terintegrasi (Maliga dan Hamid, 2019). Kondisi demografi Desa Kukin dihuni oleh 414 Kepala Keluarga dengan kategori salah satu desa yang memiliki kepadatan jumlah penduduk. Selain itu, desa ini juga memiliki wilayah yang berada pada pesisir pantai dan melewati saluran drainase. Dengan demikian, penelitian ini dikhususkan untuk menganalisis permasalahan sanitasi layak yang meliputi sanitasi layak, air bersih dan sarana pembuangan sampah di Desa Kukin.

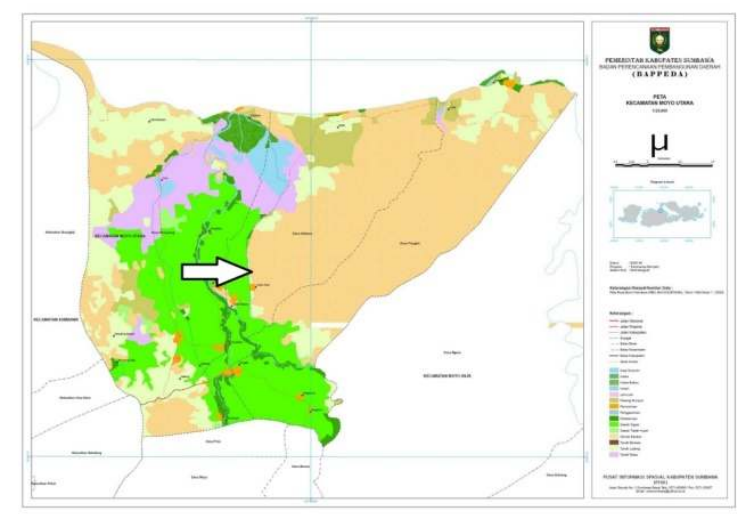

Gambar 1. Peta Lokasi Penelitian

Keterangan $\Rightarrow$ : Lokasi Penelitian

Sumber: Data Primer, 2021

Wilayah penelitian merupakan salah satu wilayah yang belum mendapatkan akses pelayanan truk sampah meskipun wilayah TPS tidak jauh dari wilayah ini. Sehingga, hasil analisis 
data menunjukkan bahwa masyarakat belum melakukan pengelolaan sampah tetapi masih terbatas pada proses pembuangan di lahan kosong sebanyak $52,5 \%$ dan dibakar sebanyak $30 \%$. Permasalahan fasilitas terkait sarana dan prasarana masih menjadi faktor utama dalam buruknya pengelolaan sampah yang ada di wilayah penelitian. Tingkat pendidikan responden yang rata-rata didominasi oleh lulusan sekolah dasar berpeluang akan mempengaruhi pola pikir masyarakat dan cara mengelola sampah. Warga terbiasa hanya mengetahui cara mengelola sampah dengan dibakar tanpa adanya pengolahan lebih lanjut tanpa menyadari bahaya pembakaran sampah dan dampak dari penumpukan sampah yang dibiarkan begitu saja.

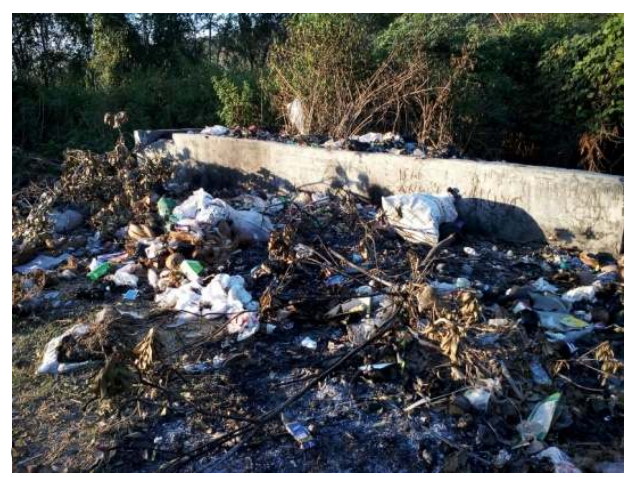

Sumber : Dokumentasi Pribadi, 2021

Tabel 4. Hasil Sampling Sampah Harian

\begin{tabular}{|c|c|c|}
\hline No & Hari ke & $\begin{array}{l}\text { Jumlah timbulan } \\
\text { sampah per hari }(\mathrm{kg})\end{array}$ \\
\hline 1 & 1 & 40,50 \\
\hline 2 & 2 & 25,70 \\
\hline 3 & 3 & 42,67 \\
\hline 4 & 4 & 39,56 \\
\hline 5 & 5 & 25,40 \\
\hline 6 & 6 & 38,60 \\
\hline 7 & 7 & 41,50 \\
\hline \multicolumn{2}{|c|}{ Total timbulan sampah } & 228,23 \\
\hline \multicolumn{2}{|c|}{$\begin{array}{l}\text { Rata-rata timbulan } \\
\text { sampah harian }\end{array}$} & $32,60 \mathrm{~kg}$ \\
\hline \multicolumn{2}{|c|}{$\begin{array}{l}\text { Rata-rata timbulan } \\
\text { sampah per rumah }\end{array}$} & $0,82 \mathrm{~kg}$ \\
\hline \multicolumn{2}{|c|}{ Densitas sampah } & $190 \mathrm{~kg} / \mathrm{m}^{3}$ \\
\hline
\end{tabular}

Sumber: Data Primer, 2021

Proses pengambilan sampling jumlah sampah dilakukan selama satu minggu dengan melibatkan 40 sampel rumah tangga yang ada di
Desa Kukin. Berdasarkan hasil pengolahan data didapatkan bahwa setiap rumah dirata-ratakan menghasilkan sampah sebanyak 0,82 kg per hari. Sedangkan untuk densitas sampah, dicari dengan rumus di bawah ini

$\rho=\frac{m}{V}$

dimana:

$\rho=$ densitas sampah $\left(\mathrm{kg} / \mathrm{m}^{3}\right)$

$\mathrm{m}=$ berat sampah $(\mathrm{kg})$

$\mathrm{v}=$ volume sampah sebesar $1,2 \mathrm{~m}^{3}$ untuk pemukiman.

Berdasarkan hasil perhitungan, maka densitas sampah yang didapatkan sebesar 190 $\mathrm{kg} / \mathrm{m}^{3}$

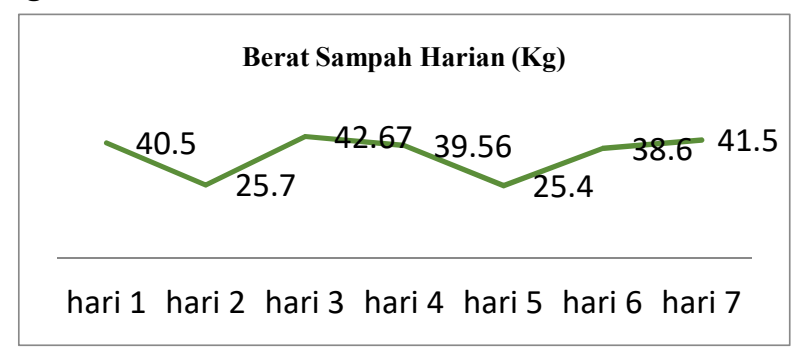

Sumber: Data Primer, 2021

Tabel 5. Komposisi dan Karakteristik Sampah

\begin{tabular}{lcc}
\hline \multicolumn{1}{c}{ Jenis Sampah } & $(\%)$ & Karakteristik \\
\hline Dapat dikomposkan & 65,20 & Organik \\
\hline Plastik & 20 & Anorganik \\
\hline Kertas & 4,90 & Organik \\
Logam & 1,50 & Anorganik \\
\hline Kaca & 0,25 & Anorganik \\
\hline Kain & 0,25 & Organik \\
\hline Kayu & 5,20 & Organik \\
\hline Karet & 0,20 & Anorganik \\
\hline popok bayi & 2,50 & Anorganik \\
\hline Total & 100 & \\
\hline
\end{tabular}

Sumber: Data Primer, 2021)

Berdasarkan Tabel 5, menunjukkan komposisi dan karakteristik sampah mayoritas organik yang dapat dikomposkan sebanyak 65,2 \%. Menurut Tchobanoglous (1993) dalam Dewilda (2014), menyatakan semakin sederhana pola hidup masyarakat semakin banyak komponen sampah organik (sisa makanan, dan 
lain-lain). Semakin besar dan beraneka ragam aktivitas sebuah kota, semakin kecil proporsi sampah yang berasal dari kegiatan rumah tangga yang umumnya didominasi sampah organik. Menurut Darmasetiawan (2004) dalam Ramandhani (2011), pada umumnya negaranegara berkembang memiliki karakteristik sampah dengan kompisisi organik yang lebih tinggi dibandingkan dari negara dengan tingkat perekonomian yang lebih maju. Desa Kukin berada pada wilayah propinsi yang ada di Indonesia yang termasuk dalam negara berkembang.

\section{Karakterisasi Dampak}

Karakterisasi dilakukan dengan menggunakan:

1. Urutan masalah lingkungan utama menurut US EPA yang dapat disimpulkan sebagai berikut:

a. sampah kertas, dan plastik berpotensi menimbulkan dampak utama lingkungan prioritas tinggi;

b. Sampah makanan dan halaman, tekstil, logam, berpotensi menimbulkan dampak sedang

2. Berdasarkan kajian mengenai hubungan stressor dengan dampak yang ditimbulkan; bahan bakar, sampah kertas, plastik, sampah makanan dan halaman berpotensi menimbulkan gangguaan keseimbangan ekologi dan kesehatan manusia.

Proses prediksi dampak negatif yang terjadi terhadap lingkungan dengan menggunakan metode matriks sebagai akibat dari penimbunan sampah di wilayah Desa Kukin sebagai berikut:

1. Kondisi geofisik meliputi: Aroma/bau sampah yang tidak sedap, air lindi (leachate), debu dan asap pembakaran sampah.

2. Kondisi biotis meliputi kondisi flora dan fauna yang terdampak akibat timbulan sampah

3. Kondisi sosial, ekonomi dan budaya meliputi estetika lingkungan, kondisi kesehatan masyarakat, sikap, budaya dan perilaku masyarakat.

Air lindi merupakan air yang terbentuk dalam timbunan sampah yang melarutkan banyak senyawa sehingga memiliki kandungan pencemar yang sangat tinggi, khususnya zat organik (Apriyani dan Lesmana, 2019). Jika dibiarkan secara terus menerus, air lindi dapat menimbulkan bau tidak sedap dan mencemari permukaan tanah. Selain itu Mulasari dan Sulistyawati (2014), mengatakan bahwa pencemaran lingkungan seperti asap hasil pembakaran sampah dipersepsikan oleh orang secara simpel bahwa pengolahan sampah adalah dengan dibakar. Bahaya sampah yang lain seperti penyakit belum menjadi pemikiran masyarakat. Dampak sampah sangat luas. Sampah dapat berdampak kepada kredibilitas pemerintah, sosial kemasyarakatan, lingkungan, kesehatan, ekonomi, bahkan pariwisata.

Berdasarkan hasil wawancara dengan key informan dan pengamatan langsung di lapangan, ditemukan bahwa beberapa faktor yang menjadi penyebab tingginya volume sampah harian sampah yang ada di Desa Kukin Kecamatan Moyo Utara adalah penduduk yang cenderung mengabaikan pentingnya pengelolaan serta daur ulang sampah, kurangnya tingkat pemahaman dan pendidikan, dan kurangnya akses pengangkutan sampah dari pemerintah.

\section{KESIMPULAN DAN SARAN}

Berdasarkan hasil penelitian didapatkan bahwa rata-rata timbulan sampah harian sebesar $32,6 \mathrm{~kg}$. Rata-rata timbulan sampah harian per orang $0,82 \mathrm{~kg}$. Densitas timbulan sampah sebesar $190 \mathrm{~kg} / \mathrm{L}$. Sampah kertas, dan plastik berpotensi menimbulkan dampak utama lingkungan prioritas tinggi; sampah makanan dan halaman, tekstil, logam, berpotensi menimbulkan dampak sedang

\section{DAFTAR PUSTAKA}

Apriyani, N., \& Lesmana, R. Y. (2019). Jumlah Timbulan dan Komposisi Sampah di 
Kelurahan Pahandut Kota Palangka Raya serta Dampaknya terhadap Kualitas Air Lindi. Media IImiah Teknik Lingkungan (MITL), 4(1), 5-9. https://doi.org/10.33084/mitl.v4i1.648

Badan Standarisasi Nasional. 2008. Pengelolaan Sampah di Pemukiman. SNI 3242:2008.

Damanhuri, Enri. 2005. Pengukuran Timbulan, Komposisi dan Karaktersitik Sampah. Ganesha, Bandung.

Dewilda, Y, Darnas, Y, dan Zulfa, I. 2014. Studi: Satuan Timbulan Dan Komposisi Sampah Domestik Kabupaten Tanah Datar. Online. http://lingkungan.ft.unand.ac.id/images/fil eTL/Dampak\%2011-1/4-YMD\%20v.pdf.

Diakses 12 agustus 2020.

Kumala, Y.S.N dan Pawenang, E.T. 2017. Kondisi Sanitasi dan Kepadatan Lalat Kantin Sekolah Dasar Wilayah Kerja Puskesmas Kedungmundu. Jurnal of Health Education JHE 2(1) (2017) http://journal.unnes.ac.id/sju/index.php/jh ealthedu/.

Lesmana, R. Y. (2017). Estimasi Laju Timbulan Sampah dan Kebutuhan Landfill Periode 2018-2027 (Studi Kasus Kec. Mentawa Baru Ketapang, Kab. Kotawaringin Timur, Kalimantan Tengah). Media IImiah Teknik Lingkungan (MITL), 2(2), 20-24. https://doi.org/10.33084/mitl.v2i2.124

Maliga, I dan Hamid, A. 2019. Analisis Permasalahan Sanitasi Pada Desa Kukin Kecamatan Moyo Utara. Media IImiah Teknik Lingkungan Volume 4, Nomor 2, Agustus 2019. Hal.51-57.

Masrida, R. 2017. Kajian Timbulan Dan Komposisi Sampah Sebagai Dasar Pengelolaan
Sampah Di Kampus li Universitas Bhayangkara Jakarta Raya. Journal of Env. Engineering \& Waste Management 2 (2): 69-78.

Mulasari, S.A dan Sulistyawati. 2014. Keberadaan TPS Legal dan TPS llegal di Kecamatan Godean Kabupaten Sleman. Jurnal Kesehatan Masyarakat Kemas 9 (2) (2014) 122-130

Http://Journal.Unnes.Ac.Id/Nju/Index.Php/ Kemas

Ramandhani, Tri Astuti. 2011. Analisis Timbulan dan komposisi sampah rumah tangga di kelurahan mekar jaya (Depok) dihubungkan dengan tingkat pendapatanpendidikan-pengetahuan-sikap-perilaku masyarakat. SKripsi. (Online). http://lib.ui.ac.id/file?file=digital/2028215 6-S705-Analisis\%20timbulan.pdf diakses 12 Agustus 2020

Sistem Informasi Pengelolaan Sampah Nasional. 2020. Diakses pada link http://sipsn.menlhk.go.id/ pada tanggal 15 Juni 2020 pukul 17.00 WITA.

Trihadiningrum, Y., Laksono, I. J., Dhokhikah, Y., Moesriati, A., Radita, D. R. and Sunaryo, S. (2015) 'Community activities in residential solid waste reduction in Tenggilis Mejoyo District, Surabaya City, Indonesia', Journal of Material Cycles and Waste Management. Springer Japan. doi: 10.1007/s10163-015-0440-5.

Windraswara, R dan Prihastuti, D. A. B. Analisis Potensi Reduksi Sampah Rumah Tangga untuk Peningkatan Kualitas Kesehatan Lingkungan. Unnes Journal of Public Health 6 (2) (2017) pISSN 2252-6781 elSSN 25847604. 